\title{
A modern day panopticon: using power and control theory to manage volunteer tourists in Bolivia
}

Thompson, Jamie

Curran, Ross

O'Gorman, Kevin D.

This is the accepted manuscript $\odot$ 2017, Elsevier

Licensed under the Creative Commons Attribution-NonCommercial-

NoDerivatives 4.0 International: http://creativecommons.org/licenses/bync-nd/4.0/

(cc) EY-NC-ND

The published article is available from doi:

https://dx.doi.org/10.1016/j.tmp.2017.01.003 


\title{
A Modern Day Panopticon: Using power and control theory to manage volunteer tourists in Bolivia
}

\author{
Jamie Thompson $^{\text {a }}$ \\ Ross Curran ${ }^{b^{*}}$ \\ Kevin D O'Gorman ${ }^{\text {a }}$ \\ ${ }^{a}$ School of Social Sciences, Heriot-Watt University, Edinburgh, UK \\ ${ }^{\mathrm{b}}$ Dundee Business School, University of Abertay, Dundee, UK. \\ *Corresponding Author: Ross Curran r.curran@abertay.ac.uk
}

\section{Abstract}

Volunteer tourism literature is yet to examine the impact of power and control practices on volunteer tourist compliancy. This paper contributes to closing this research gap by proposing and testing a new theoretical model of power and control practices. Drawing upon the previously un-synthesized theoretical contributions of Foucault (1979) and French \& Raven (1959), the model presents power and control practices identified in the extant organizational literature. Using an auto-ethnographic approach, data was collected within a Bolivian volunteer-host community. Examination of results suggested mutually beneficial volunteerhost working relationships occur under 'softer' management practices. Our findings also offer insight into the salience of using reward-based management strategies as a control mechanism, as well as identifying two new control practices that emerged empirically. The research suggests several implications for the management of host communities towards creating more harmonious, efficient, and effective working relationships between volunteer tourists and hosts.

\section{Highlights}

- Investigates the impact of power and control practices on volunteer tourist compliancy.

- Develops a new theoretical model of power and control practices.

- Applies the model to a volunteer project in Bolivia.

- Advances understanding of volunteer tourist management.

Key Words

Volunteer tourism; power and control; volunteer management; Bolivia 


\section{A Modern Day Panopticon: Using power and control theory to manage volunteer tourists in Bolivia}

\section{Introduction}

Tourists seeking more authentic, rewarding, and worthwhile experiences have stimulated continuing development of the volunteer tourism sector (Barbieri, Santos, \& Katsube, 2012 Otoo \& Amuquandoh, 2014). The academic literature has developed in tandem, but is weighted toward understanding motivations, method, and wider cultural impacts of volunteer tourism, rather than the challenging task of managing the often complex volunteerhost dynamic (Wearing \& McGehee, 2013). This research contributes to our limited understanding of how power and control practices inform effective volunteer management, and their role in eliciting greater levels of volunteer compliancy.

Uniquely, volunteer tourism offers volunteers an opportunity to combine leisure, travel, and volunteer work (Barbieri, et al., 2012; Tomazos \& Butler, 2012), rendering the already complex task of managing volunteers in conventional settings (Curran, Taheri, MacIntosh, \& O'Gorman, 2016), even more challenging. This can be attributed to the particular volunteer-host dynamic formed as a result of significant personal investment on behalf of volunteer tourists, coupled with the need for hosts to ensure required tasks are completed, and volunteers contribute appropriately to projects that depend upon physical and emotionally demanding work (Alexander, 2012; Barbieri, et al., 2012). Consequently, sustaining mutually beneficial volunteer-host relationships for the duration of a volunteers placement is a complex, potentially frictional process, aggravated through the inequality of the specific dynamics found within a volunteer tourism context (Terry, 2014; Tomazos \& Butler, 2012). Failure to manage these relationships successfully can result in noncompliance of volunteers, and negative consequences for volunteer tourists, managers, and the prospective beneficiaries of planned projects (Barbieri, et al., 2012; Sin, 2009; Tomazos \& Butler, 2012). Thus necessitating further investigation exploring volunteer tourist host dynamics and the applicability of power and control theory.

Power and control (French and Raven 1959) explores superior-subordinate relationships and identifies promotion prospects, wage scale, and employment termination as stimulators of compliance (Cadsby, Song, \& Tapon, 2007; Choi \& Peng, 2014; Deckop, Mangel, \& Cirka, 1999; Degiuli \& Kollmeyer, 2007; Vázquez, 2006). Separate from French 
and Raven (1959), Foucault (1979) has contributed to understanding power and control, yet both tracks of literature have yet to be synthesized.

Thus this research contributes by expanding knowledge of power and control principles among volunteers (Tomazos \& Butler, 2012), to develop more effective and sustainable host community projects (Terry, 2014). Specifically, this is achieved through developing and testing a new management framework, bringing together two strands of power and control literature for the first time, within a unique context. The paper is organized as follows: a brief discussion is offered of the prevailing volunteer tourism literature, alongwith consideration of the theoretical underpinnings of power and control. Next, the methodological approach employed in this research is presented, followed by our empical findings. The final sections highlight the relevance of our study to current literature and offer the theoretical, and practical implications as well as a summary of the study's limitations.

\section{Literature Review}

Volunteer tourists are defined by Wearing (2001, p.1) as "those tourists, who for various reasons, volunteer in an organised way to undertake holidays that might involve aiding or alleviating the material poverty of some groups in society." The researchers commissioned the paring website Workaway to facilitate the discovery of the host community used for this study, and subsequently deemed an ecological project in Bolivia suitable. This form of nonstaged volunteering (similar to Willing Workers on Organic Farms (WWOOF) programmes) requires volunteers work set hours in return for food and accommodation, with hosts benefiting economically from work conducted (Streifeneder, 2016).

After an advocacy period of volunteer tourism, research began to comment on potential negative effects on host communities (Wearing \& McGehee, 2013). Terry (2014) notes that negative dynamics within volunteer-host relationships often stem from either volunteer indolence or perceived inadequate provision of amenities by a host. McGehee (2014) proclaims that this dichotomous debate between altruistic and hedonistic volunteers - while enlightening to important issues (such as those presented by Terry) - has proven to be largely dependent upon context; suggesting future studies should focus on more sophisticated avenues of research, attempting to provide frameworks for improvement of host communities rather than merely identifying issues. Accordingly, this paper has answered this call by attempting to create 
a framework for effective relationships in the volunteer context. The complexity of the volunteer-host relationship in volunteer tourism settings is now considered.

\subsection{The Volunteer-Host Relationship}

The ideal quintessential relationship between host and volunteer should constitute a mutually beneficial agreement, toward creating an enviable cross-cultural partnership (Singh, 2012). The act of contribution by volunteers and reciprocation of gratitude from hosts can stimulate cultural, and community integration, as well as establishing cross-cultural relationships grounded upon friendship and solidarity (McIntosh \& Zahra, 2007; Zarandian, Shalbafian, Ryan \& Bidokhti, 2016). However in order for effective and mutually beneficial relationships to evolve, positive contribution by volunteers should not only be viewed as potential, but rather an inevitable outcome of the interaction (Guttentag, 2012). The commercialisation of a supposed altruistic activity has often led to ineffective working environments, whereby large organisations find it easier to market projects that incite high expectations with no code of conduct condemning inappropriate or obstructive behaviour from volunteers (Grimm \& Needham, 2012; Nyahunzvi, 2013; Smith \& Font, 2014). Lupoli, Morse, Bailey and Schelhas (2015) and Alexander (2012) argue that in order to resist negative counterproductive relationships, host communities must be empowered in order to take control of their own projects. Lupoli et al (2015) argue for a bottom-up organisational structure that empowers host communities to take control and be the administrators of their own community.

Such volunteer predilections cannot be dismissed however, as they form part of the power and control process. Motivations of volunteer tourists can range from very focussed upon poverty alleviation and altruism, towards more hedonistic pursuits whereby volunteers are motivated by the opportunity to conduct experiential activities concerning their personal self-development (Sin, 2009; Tomazos \& Butler, 2012; Otoo \& Amuquandoh, 2014). Neocolonial arguments assert that tourists have the power to regulate the host environment and cultivate norms which are unconsciously reproduced by other tourists (Hollinshead, 1999). This paper reviews effective management practices found in superior-subordinate relationships in traditional organisational structures, subsequently identifying how effective these practices are in a host community context through the use of template analysis. From the findings of this study power and control is suggested to be effective in managing volunteers and creating effective relationships, mutually beneficial for both volunteer and host community. 


\subsection{Development of Power and Control Theory}

Eisenhardt (1985) defines two separate strategies of control: Control as the process to minimize divergence of subordinates away from organizational values, and control utilized to monitor and reward subordinates dependant on performance. Setting remuneration traditionally has significant influence over a superior's ability to control subordinates, as it is management's ability to offer remuneration in return for work conducted that establishes a base level of control. Within the volunteer context, remuneration becomes inappropriate, and in the case of Workaway and WWOOF programmes this is replaced with non-financial reward alternatives such as additional food, free-time and accommodation (Streifeneder, 2016). Arguably, traditional practice encouraged managers to wrest complete organizational control away from subordinates by the use of 'hard' influences such as fear, coercion and remuneration (Berson \& Sosik, 2007). The inherent sense of power resides in the fact that labour is unskilled, all organizational knowledge belongs to managers, and any worker can potentially be replaced, resulting in persistent job insecurity and an imbalance of power in favour of employers (Choi \& Peng, 2014; Vázquez, 2006). Authors maintain that bureaucratic mechanisms can remain effective under particular market conditions (Styhre; 2008; Walton, 2005), specifically recognising employee ability to exhibit social adaptability and proactive voice as being contextually important factors in employee compliance under coercive control (Frieder, Hochwater \& DeOrtentiis, 2015; Mackey, Ellen, Hochwater \& Ferris, 2013). Podsakoff, Todor, Grover and Huber (1984) claim bureaucratic forms of punishment and reward if administered appropriately (contingent upon performance) generate positive effects on subordinate compliancy and organizational commitment.

Foucault (1979) developed an alternative sociological perspective explaining how the power concept is developed through social 'norms.' Foucault perceived power not as a concept that must be forced or repressive in nature (Gaventa, 2003), but rather a consistent presence producing social discipline and conformity through implementing codes of social norms (Foucault, 1991). Foucault's (1979) interpretation represents a development of Bentham's (1791) panopticon. Foucault (1979) notes how prisoners would become accustomed to observation, to the extent that even when not under the 'panoptic gaze' they aligned their attitudes with social norms to become 'self-disciplined' (Elmes, Strong, \& Volkoff, 2005). Such social control induces rational compliance from individuals who aim to avoid punishment and seek reward from the ever-present panoptic mechanism (Raven, 1999), and in the context 
of tourism the tourist gaze (Hollinshead, 1999). Sewell and Wilkinson (1992, p107) describe how once subordinates align their personal goals with that of the management system, disobedience recedes as workers are no longer 'defending the frontier of control.' The modern day panopticon manifests in numerous forms including team-working, open plan offices, and computer monitoring systems (Ball \& Wilson, 2000; Sewell, 1998), facilitating managerial or peer surveillance, and forcing employees conformity to with organizational expectations. Investigations into forms of normative control show negative and adverse associations with such approaches. Mann, Nolan and Wellman (2003) coin the term 'sousveillance' describing how individuals are likely to resist and rebel against forms of panoptic surveillance while Fleming and Sturdy (2009) and Kunda (1992) identify subjective resistant responses present in employee behaviour stemming from the lack of authenticity of normative controls and responses include cynicism of the control as well as attempts to undermine the normative control sentiment.

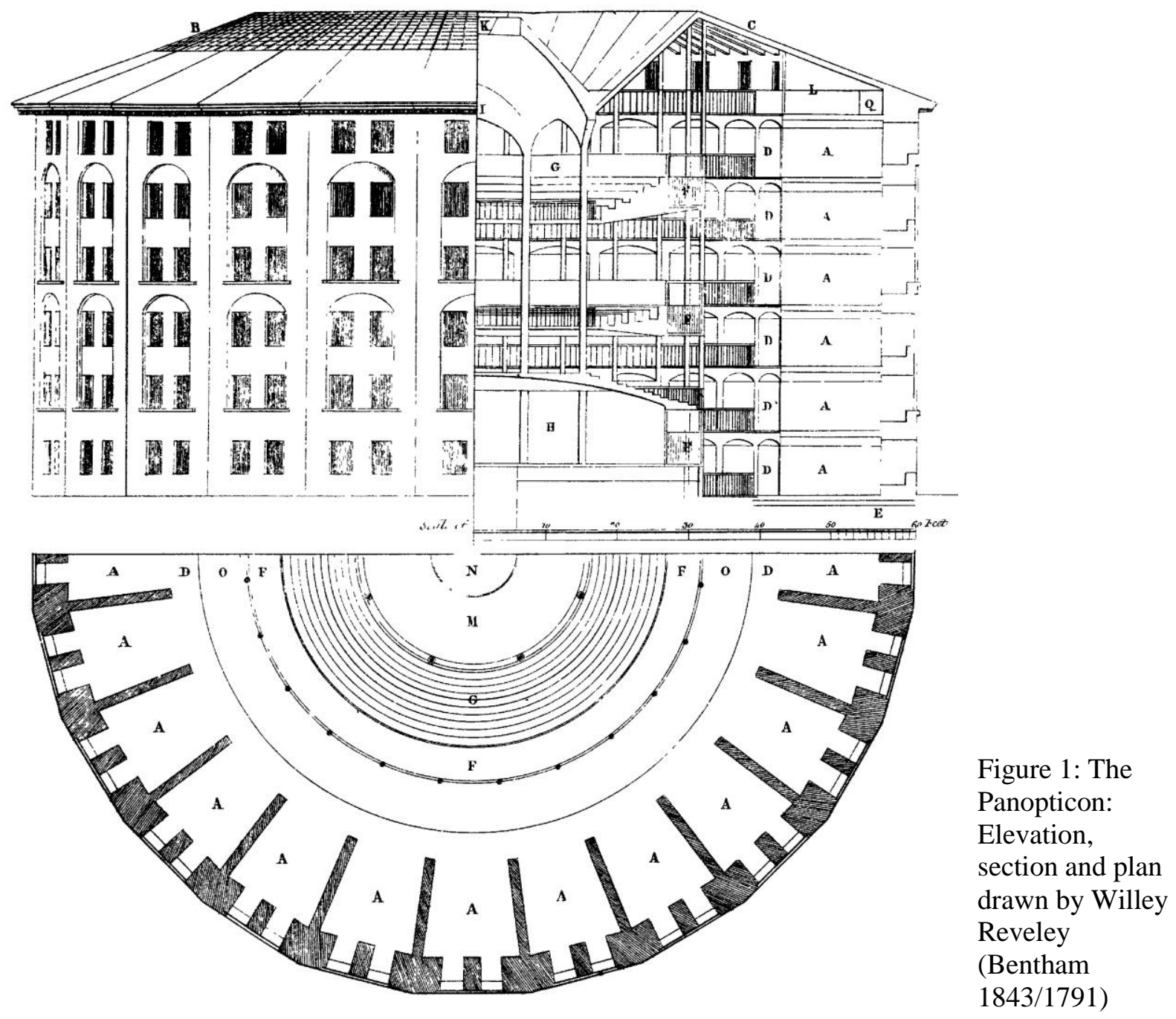


Power and control approaches have continued to evolve in contemporary management practice. Organizations have seen the rise of HRM practices creating intimate working environments in an attempt to placate subordinates (Preuss et al., 2009). These so-called 'soft' practices of power and control attempt to create a working environment incorporating a willingness from subordinates to comply with organizational culture supported through strong internal workplace relationships (Berson \& Sosik, 2007). Contemporary literature posits exertion of 'soft' instructive principles of power create shared meaning and shared goals, resulting in control practices with greater advantages for both the subordinates and the organization (Jensen \& Raver, 2012; Loi, Lai, \& Lam, 2012; Shamir \& Lapidot, 2003). This instructive power aims to seduce, entice, and persuade individuals to comply with organizational codes and values through multilateral trusting relationships, strong communication links, and the desired expertise of superiors (Reed, 2001; Shamir \& Lapidot, 2003). Deviation from these social norms is calculated to induce undesirable feelings of embarrassment, anxiety, and guilt (Hechter, 2008). Styhre (2008) notes that such approaches to organizational control are generally commended in the literature for stimulating work diversity and challenging employees.

\subsection{Literature Summary}

The extant literature attests to contextual influences occurring in call centres (Fleming \& Sturdy, 2011; Kinnie, Hutchinson, \& Purcell 2000), family run businesses (Ainsworth \& Cow, 2003), healthcare (Coombs, Knights, \& Willmott, 1992; Iedema \& Rhodes, 2010), hightech industries (Golden \& Veiga, 2008; Lines, 2007), manufacturing (Elmes et al., 2005; Iedema, Rhodes, \& Scheeres 2006), the military (Shamir \& Lapidot, 2003), sales (Loi, et al., 2012; Vázquez, 2006), students (Subašić, Reynolds, Turner, Veenstra, \& Haslam 2011; Tenbrunsel \& Messick, 1999), temporary workforces (Degiuli \& Kollmeyer, 2007; Sanchez \& Toharia, 2000), and in less economically developed countries (Mulinge, 2001). Despite these efforts, research on power and control in the volunteer-host relationship within a tourism context has continued to be overlooked. This relationship goes beyond authentic interactions, and represents a genuine exchange (McIntosh \& Zahra, 2007; Streifeneder, 2016), necessitating a new consideration of power and control, underpinned by the notion that 
influences affecting volunteers differ considerably from those influencing traditional wage earners.

The preceding literature review introduced volunteer tourism, and charted the development of power and control management theory, with particular focus placed on the contributions by Foucault, and French and Raven. The literature review also demonstrated a lack of understanding regarding volunteer management within a tourism context, specifically, managing power and control relationships affecting volunteer-host dynamics. To contribute to closing this gap, the extant literature is synthesized for the first time to create a new model of power and control principles, contextualized to apply to volunteer-host dynamics. Our contextualized model (Table 1) is anchored upon the most widely applied contributions from French and Raven (1959), and latterly Raven (1965), which comprise of five and six principles respectively, but remain criticized for non-conclusiveness, thematic overlap, and a propensity for producing inconsistent results (Podsakoff \& Schriesheim, 1985). Stemming from Foucault's (1979) contributions to the field, the model also incorporates the theme of surveillance as representing an additional method of exerting power and control over volunteers, combining the two previously independent strands of power and control theory by Foucault, and French and Raven. More recent attempts at model refinement (Raven 1992; 1993) have resulted in inclusion of eleven power principles, although their relevance to the volunteer tourism context remains questionable, and their usefulness to exploratory stage research limited. Consequently, the principles incorporated in our model are conducive to developing understanding of how workplace control practices, workplace culture, and external organizational factors interact with the social identities of subordinates toward inducing a level of compliance, and represent an extension beyond interpersonal relationship dynamics between influence, and influencer (Raven, 2008). Further, contextually specific themes relevant to overall subordinate compliance are identified.

Table 1: Volunteer Power and Control Model

\begin{tabular}{|l|l|l|}
\hline Influence & Findings & Source \\
\hline Coercion & Contingent punishment is a prevalent & Crowley, 2012; Podsakoff \& Todor, 1985; \\
& workplace practice. Coercion can reduce & Podsakoff et al., 1982; 1984; Schnake, \\
& deviation. When opportunities to rebel & 1986; Tenbrunsel \& Messick, 1999; \\
& against authority arise, coercion is associated & Trevino, 1992. \\
& with reductions in effort. & \\
\hline
\end{tabular}




\begin{tabular}{|c|c|c|}
\hline Job Security & $\begin{array}{l}\text { Job insecurity can lead to opportunist } \\
\text { management practices. Consequently } \\
\text { managers can wield high control over } \\
\text { replaceable unskilled workers. This can } \\
\text { result subservient workforces, or non- } \\
\text { committed employees accepting dismissal. }\end{array}$ & $\begin{array}{l}\text { Choi \& Peng, 2004; Degiuli \& Kollmeyer, } \\
\text { 2007; Sanchez \& Toharia, 2000; Vázquez, } \\
\text { 2006. }\end{array}$ \\
\hline Surveillance & $\begin{array}{l}\text { Degrees of surveillance that promote self- } \\
\text { management and self-discipline may have a } \\
\text { positive effect on managerial control, while } \\
\text { invasive surveillance will produce negative } \\
\text { responses. }\end{array}$ & $\begin{array}{l}\text { Elmes et al., 2005; Foucault, 1979; } \\
\text { Iedema et al., 2006; Iedema \& Rhodes, } \\
\text { 2010; Jensen \& Raver, 2012; Kinnie et al., } \\
2000 .\end{array}$ \\
\hline $\begin{array}{l}\text { Communication } \\
\text { with } \\
\text { Administrators }\end{array}$ & $\begin{array}{l}\text { Enhanced leader-membership exchange } \\
\text { relationships reduce deviance from } \\
\text { subordinates, increasing commitment and } \\
\text { performance. }\end{array}$ & $\begin{array}{l}\text { Golden \& Veiga, 2008; Goldstein \& } \\
\text { Hays, 2011; Kacmar, Witt, Zivnuska, \& } \\
\text { Gully, 2003. }\end{array}$ \\
\hline Trust & $\begin{array}{l}\text { Building multilateral trusting relationships } \\
\text { between managers and subordinates ensures } \\
\text { employee organizational commitment, } \\
\text { reducing deviation from managerial control. }\end{array}$ & $\begin{array}{l}\text { Jensen \& Raver, 2012; McCauley \& } \\
\text { Kuhnert, 1992; Reed, 2001; Shamir \& } \\
\text { Lapidot, 2003; Subašić et al., } 2011\end{array}$ \\
\hline $\begin{array}{l}\text { Intimate working } \\
\text { environment }\end{array}$ & $\begin{array}{l}\text { Autonomous working environments afford } \\
\text { managers high levels of control over } \\
\text { subordinates through employee disinclination } \\
\text { to resist 'family culture' through fostering } \\
\text { guilt. This can cover-up more coercive forms } \\
\text { of control. }\end{array}$ & $\begin{array}{l}\text { Ainsworth \& Cox, 2003; Casey, 1999; } \\
\text { Fleming \& Sturdy, 2011; Kinnie et al., } \\
\text { 2000; Loi et al., } 2012\end{array}$ \\
\hline Expertise & $\begin{array}{l}\text { Knowledge asymmetry encourages } \\
\text { subordinates to follow managerial control. } \\
\text { Subordinates are more likely to follow } \\
\text { experienced managers based on credibility } \\
\text { and learning opportunities. }\end{array}$ & $\begin{array}{l}\text { Coombs et al., 1992; Elangovan \& Xie, } \\
\text { 1999; Lines 2007; Rahim, 1989; Taskin \& } \\
\text { Bunnen, 2015. }\end{array}$ \\
\hline Reward & $\begin{array}{l}\text { Management's ability to issue bonuses, } \\
\text { benefits and reward schemes provide greater } \\
\text { levels of productivity and commitment } \\
\text { among subordinates if contingent upon } \\
\text { performance. }\end{array}$ & $\begin{array}{l}\text { Cadsby et al., 2007; Deckop et al., 1999; } \\
\text { Igalens \& Roussel, 2000; Levine, 1992; } \\
\text { Mulinge, 2001; Podsakoff et al., } 1982 .\end{array}$ \\
\hline
\end{tabular}

\section{Methodology}

The auto-ethnographic approach used is informed by interviews and observations of volunteers and host community managers, guided by our synthesized model of power and control principles (Table 1). Fieldwork was conducted in July 2015,60km from Cochabamba, Bolivia. The site, administered by an NGO organization was identified through the popular volunteer-host matching website Workaway.info. While a limited number of previous 
volunteer tourism research has been positioned in South America, it has generally omitted the Bolivian context. Furthermore Bolivia, which is culturally and economically distinct from its neighbours, partly due to its underdeveloped leisure industry (Boniface \& Cooper, 2005), represents an authentic and unique research setting.

Data collection consisted of participant observations, augmented with 22 semistructured interviews (with volunteer tourists) during the shared project. Observational data collection allowed the researcher scope to update field notes regularly, varying from in-thefield work attitudes to post-hoc reflections of work conducted; which when collaborated provided relevant perspectives for the data analysis (O'Gorman and MacIntosh, 2015). The interviews, designed to support the observations, were conducted in private, away from other volunteers and managers, the locations of the interviews varied between in-the-field, and leisure-time settings, deemed important as people can construct individualized social identities influenced by contextual surroundings (O'Gorman, MacLaren and Bryce, 2014) and concluded when data saturation was judged to be reached (Bowen, 2008).

To analyse the data, a template analysis approach was used, which involves comparison between the results of the literature review, and the collected empirical data (Butler, Curran, \& O'Gorman, 2013; McMillan, O'Gorman, \& MacLaren, 2011). While the initial template is derived from a priori themes identified in the literature (See Table 1), template analysis is flexible and allows additional themes and evidence emerging from the data to be included $a$ posteriori (Butler et al., 2013). The a priori themes provided a set of anticipatory results, thus providing a basis for observation when immersed in the ethnographic field while also acting as a guiding structure for interviews. This allowed the researcher to ask questions relating to the extent the themes were relevant to this particular volunteer tourist context, while the semistructured nature of the interviews and immersion into the host community afforded the researcher the opportunity to pursue emerging avenues of insight. Consequently, two additional themes (the delegation of work, and the establishment of freewill) were identified within the data but previously absent in the literature. Practically, the analysis of the interview transcripts allowed the researchers to determine the extent of empirical support for the template by categorizing appropriate sections of text in relation to the template themes. 


\section{Findings}

Findings are structured around the themes derived from a comprehensive literature review, presented in Table 1. Following established ethical conventions, names denoting the provenance of quotations have been replaced with pseudonyms. In keeping with the exploratory character of the research an open mind-set was maintained throughout the data collection, allowing for the emergence of two additional themes (the delegation of work and the establishment of freewill) that were not derived from the literature, but stem from the studies empirical component. The central themes to emerge from the data analysis were:

\subsection{Coercion}

Coercive forms of power were shown to be ineffective controls in this volunteer context. Initially upon entering the host community Camila (a host community manager) was questioned about rules that exist to which she replied, "any persons found in the possession of alcohol would be asked to leave." This rule was quickly found to constitute an empty-threat. The understanding of volunteers was that: "you're not offending anyone, so long as you're not [drinking] on the job." These comments echo suggestions in the literature that subordinates are likely to rebel against forms of coercive control they interpret as unreasonable (Podsakoff et al., 1984). Additionally, volunteers explained that they did not feel like they could be forced into any work, noting that: "if you don't want to [work] you can just leave; if you want to leave then leave. They can't tell you you're going to do this, or you're going to do that."

\subsection{Job Security}

Similarly, volunteers developed understanding their positions were secure, despite the fact that there were a large number of incoming potential volunteers, and the volunteer community operates at a high capacity in regards to accommodation. Choi and Peng (2014) and Vázquez (2006) note such scenarios represent perfect market conditions for managers to maintain control over subordinates through the persistent threat of replacement. Nevertheless, volunteers in this community had interpreted their position in the community as safe: "Camila is always bugging me about whether I'm leaving this week or not because of new applicants; I just keep saying that I'm not ready to leave yet." When probed about whether this would make her work harder for fear of being replaced, the female London volunteer replied: "No, it's a bit of a refuge isn't it? I think they lose that identity once they start kicking people out. This place is as much about peace and spirituality as it is about the work element." Host community managers echoed these sentiments stating they wanted to be perceived as harmonious and that, 
"if you put pressure on people to leave, then [volunteers] will stop coming and then who comes to work? We would lose everything we've created here."

\subsection{Surveillance}

Surveillance from administrators was seen as a necessary form of control: "Otherwise volunteers like John, Steven and Paul would just lie around naked all day." This notion is supported by comments from a London volunteer who described one of the supervisors in the community as: "A bit of a hardball; a hard nut to crack, but she's a necessary evil and I guess someone has to be." More evident in the findings was the role of peer surveillance. The volunteers would become 'self-disciplined' under team working scenarios because internal reputation management forced each volunteer to individually self-discipline themselves to appear to be working hard (Sewell, 1998): "It's good just working in a two because we can chill out a bit; when weeding in the big group it's so intense." The benefits to management of peer surveillance are further evidenced by a respondent who, when commenting on group work activities noted: "Everyone tries to appear the most philanthropic and this pushes everyone."

\subsection{Communication with Administrators}

Our findings suggested high levels of communication are essential for controlling volunteers. It was apparent volunteers were more likely to comply with host community managers that constructed a low power distance relationship rather than those administrators which only gave orders.. A male volunteer from Watford reflected on the importance of a good host-volunteer relationship noting: “...here, they muck in as well and are always around to help you understand what we are doing." Furthermore, the importance of closeness between volunteer and host was evidenced through comments relating to a previous volunteer post: "In the last place I was at, this guy was telling me to chop onions for two hours while he was going off to a wine bar, so I wasn't exactly going to be giving it my all.” In a volunteer tourist destination that recruits internationally, communication through language barriers presented an additional challenge. Mayumi from Bolivia was a manager at the project who spoke limited English, and consequently avoided organizing social events. This aversion to socializing was perceived as rude by some of the volunteers, and contributed to challenges of her authority, demonstrated by a respondent noting: "She doesn't know how to speak to people; she has no people skills, just tells you to do a job." When questioned, Mayumi defended her position by stating she felt uncomfortable when in a large group but conceded that it gave her less authority, 
"[Other hosts] get on better with the volunteers and so they listen to them, but for me it is too difficult."

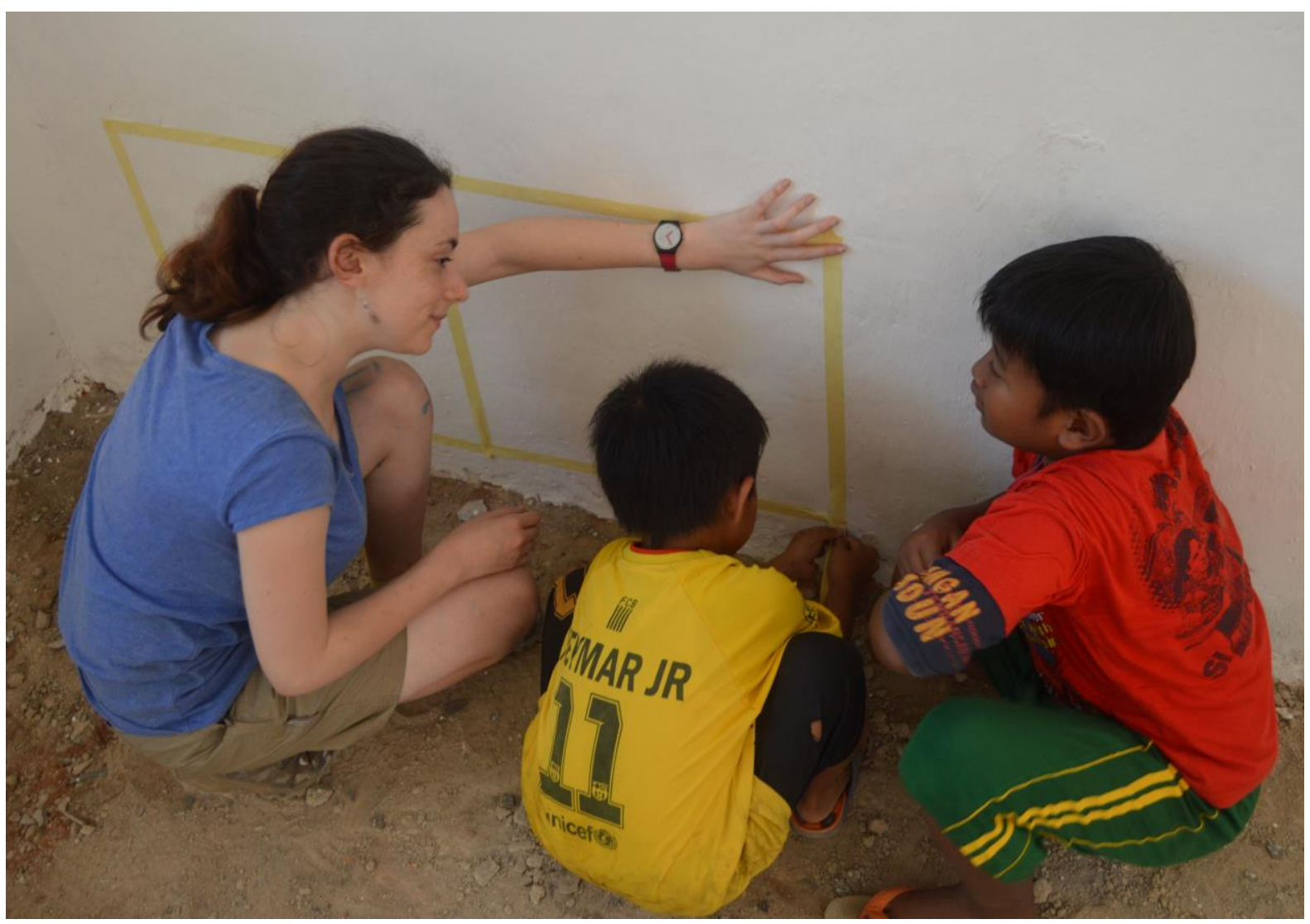

[Figure 2: Working with local children]

Photo Credit: Fergus Mitchell

\subsection{Trust}

Similar results were uncovered with regards to trust. The same host manager (Mayumi) lost the trust of the volunteers when she informed them that a day given to building the 'tamascal' would count as a day off, therefore meaning all volunteers would have to work an extra day, irate respondents contested: "It would have been okay if she had told us beforehand but telling us that now is tough and it's a bit sneaky." This incident eroded the shared social identity volunteers had previously enjoyed with the administrators, and negatively affected the otherwise committed and compliant workforce. In particular, this interaction and breakdown of multilateral trust modified the social identity of all managers toward perceptions of autocratic and shrewd management techniques. Respondents capture this notion commenting: "Everyone is discontented, no one is very happy with the decision and why should [the volunteers] be trusted to get on with work when we can't trust Mayuni to give us our days off'. 


\subsection{Intimate Working Environment}

In response to the day off disagreement, the volunteers argued that discontentment threatened to destabilise the intimate relationships between superiors and workers, commenting that: "I think if she were smart she would let this slide and give us an extra day off ...it will make the community stronger." What the volunteers previously perceived as the atmospheric and spiritual values of the setting were strong controllers in promoting compliancy, noting: "I like working here, I'm much more willing to do what these people say than feel pressured to work in the atmosphere of a half-empty hostel in Cordoba". The positive influence generated by an intimate working environment is further demonstrated by a volunteers' description:

"Everyone appreciates the ethos of this place. They like building relationships, they like helping out, getting a little in return, helping your neighbour. No one here is going to completely slack off, there would be too much guilt."

These findings show that volunteers' socially constructed working environment pressures them to conform, and deviance away from the social normative expectations is seen as a movement against the cultural environment, and would induce feelings of guilt and embarrassment (Hechter, 2008).

\subsection{Expertise}

Superiors in the community with expertise were able to exhibit a much higher level of control. It was observed that in numerous instances the owner of the community (Shaman) delegated work which took precedence over previously assigned manual volunteer duties, one volunteer reported:

"[The Shaman] asked me to translate these documents... I think the hope is that it will make the community more well-known and mean it can grow."

Any work delegated by the Shaman was perceived as much more important to the community and therefore had a greater ability to control volunteers when working on it.

Additionally the communities' long-standing volunteers (over 6 months), were expected to work an extra day per week as well as extra hours per day. In exchange for this compliance among these long-standing volunteers they received teachings about shamanism. His teaching was viewed as a worthwhile trade-off for commitment to the community and working longer hours. 


\subsection{Reward}

Rewards were found to be highly influential in exercising control over volunteers; manifesting as their accommodation and food provision. The powerful effect of rewards is demonstrated through one respondent commenting in relation to their previous volunteer experience: "We worked for 10 days constantly shovelling dirt in 30C heat", when asked what encouraged them to remain with the project they replied: "We had the whole place to ourselves, that made it good enough to stay. The food was good and we ate well". The respondent went on to convey their views on the current volunteer project: "Work is monotonous and the amount you're offered in return in respect to food is seriously lacking. How can you make volunteers work hard when you're paying them with rice?"

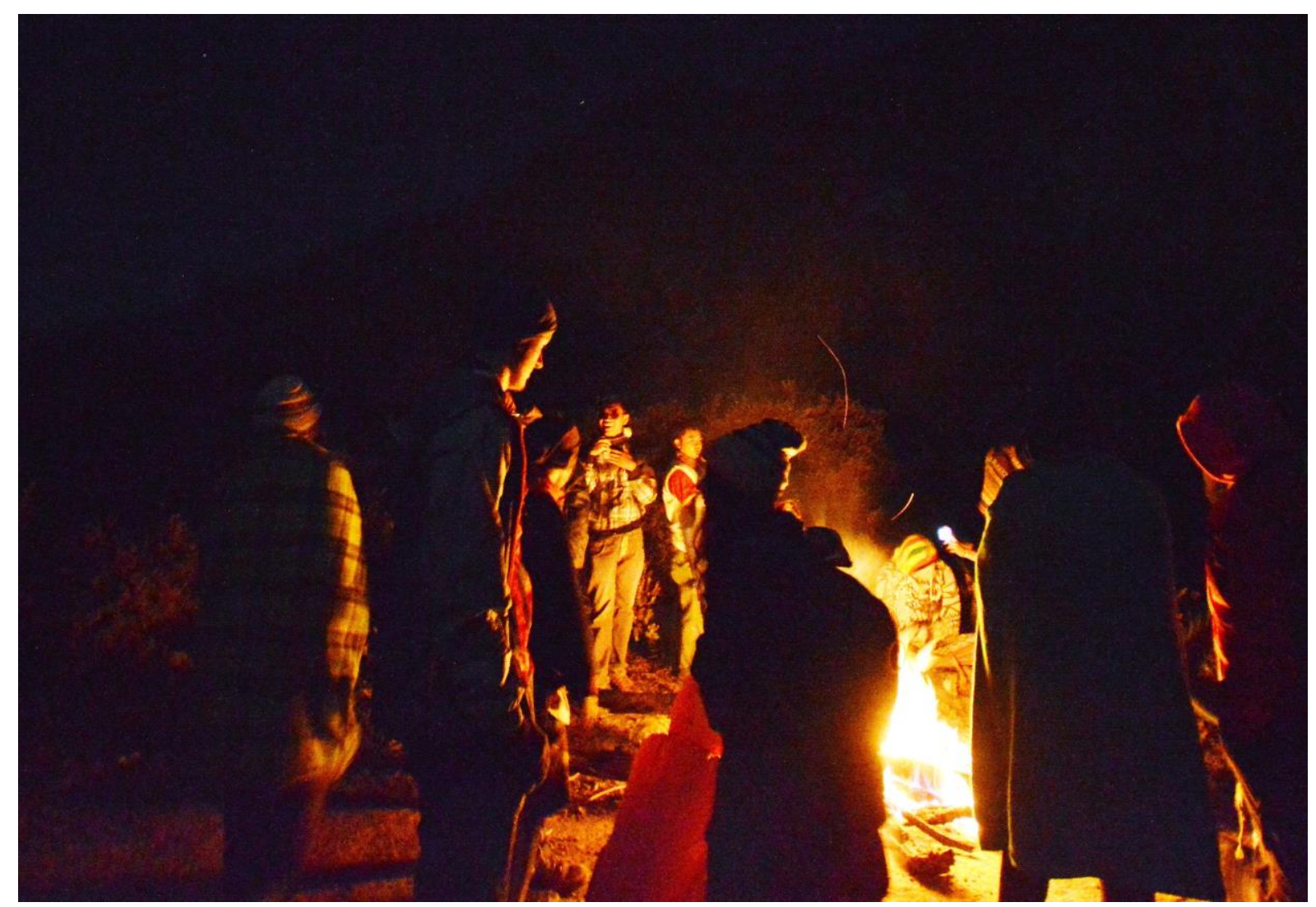

Figure 3: Relaxing after Work Photo Credit: Fergus Mitchell

The power of reward was again evident when, for a volunteer's birthday, the projects chefs used comparably luxurious ingredients for the meal the volunteer response was significant: "If they made us work a couple more hours but gave us that [food] every day I think everyone would be happier because we'd actually feel like these guys deserved our hardest level of work." Surprisingly, hosts were equally open to the prospect of offering reward, suggesting 
non-financial rewards such as facilitating activities and games would be more appropriate. It appeared obvious during the interview that the hosts did not recognise that there was discontentment over food provision. However, Hector noted that everyone seemed happier after good food the previous night, so would consider doing it again soon.

\subsection{Delegation of work}

Delegation of work enabled control over volunteers. Significant predilections toward certain jobs were exhibited by volunteers, often founded upon personal inclinations and the perceived social contribution of the tasks. This notion was evidenced through comments highlighting: "I'm a really enthusiastic person and I feel I need to be doing something valuable and outdoors, not stuck in the office at a desk like yesterday." Other respondents indicated a task-productivity association, while the idea that some tasks hold greater perceived value over others is captured in one respondent noting: "I'm still a volunteer and I want to feel like I'm putting something into the community, not just cooking meals so that everyone else can contribute." Due to the output-driven goals of traditional organisations, the majority of occupations have constrictive job roles and thus mundanity is commonplace (Hales \& Tamangani, 1996), however the potential flexibility regarding the type of work and the workforce in the volunteer sector provides comparatively more opportunity to use job delegation as a control practice. Significantly there are predilections toward less monotonous, varied work, as well as work that feels valuable and has a tangible contribution due to triggers of change in routine work having significant benefits to worker attitudes (Styhre, 2008).

\subsection{Establishing freewill}

Findings supported the establishment of freewill among volunteer tourists as an additional method of control. Stemming from theory of autonomous working environments, the interactions with autocratic superiors and rigid working hours in this case constructed an image of involuntary, obligatory volunteer work. One respondent reflected on how management had been poor in this respect: "We are here for a reason, I don't see why there is a wake-up call at 8am and someone coming around to ensure I'm volunteering in the correct manor." Many of the volunteers expressed that in other volunteering communities they were managed more informally, meaning the work fit around when they felt at their most productive:

\footnotetext{
"At the last place I was at she was really sweet and just asked us to help in 'any way we could.' This meant we woke up a bit later than here, but we worked right through the day. We felt guilty if we ever just lay about sunbathing. But
} 
here, the working hours are so strict that once the working hours are done I

don't want to see the sight of a hoe."

Our findings concur with the literature, suggesting restrictions on volunteer's freedom generate a willingness to re-establish such freedom (Stukas et al., 1999).

\section{Discussion}

Our findings suggested coercion and the establishment of job insecurity be removed from our priori model of power and control principles. Principally, they were shown to not be conducive to enhancing volunteer compliance, and held potential to foster an unwillingness to work among the volunteer cohort. Our data broadly echoed wider volunteer management literature which emphasizes the need for managers to strike a balance between hard and soft management approaches, and apply private sector practices to volunteers with caution (Studer, $\&$ von Schnurbein 2013). Furthermore, two posteriori themes that emerged from the data were included in the model; delegation of work, and the establishment of freewill, thus, the refined model reflected these changes, and is shown in Table 2.

\begin{tabular}{|l|l|}
\hline Influence & Findings \\
\hline Surveillance & $\begin{array}{l}\text { Managerial surveillance perceived as a 'necessary evil' however most } \\
\text { significant was the positive effect of peer surveillance through team- } \\
\text { working projects. }\end{array}$ \\
\hline $\begin{array}{l}\text { Communication } \\
\text { with } \\
\text { administrators }\end{array}$ & $\begin{array}{l}\text { Increased communications between superiors and volunteers produced } \\
\text { has positive effects on worker compliance and productivity. The most } \\
\text { important variable was establishing a perceived equal relationship. }\end{array}$ \\
\hline Trust & $\begin{array}{l}\text { Greater levels of trust lead to improved productivity, compliance, and } \\
\text { worker relationships. The loss of trust in the Bolivian case study leads to } \\
\text { counter-productive behaviour. }\end{array}$ \\
\hline $\begin{array}{l}\text { Intimate } \\
\text { working } \\
\text { environment }\end{array}$ & $\begin{array}{l}\text { An intimate working environment produces compliant volunteers. } \\
\text { Workers who are committed to the culture of the environment do not want } \\
\text { to deviate away from the harmonic atmosphere with deviant behaviour. }\end{array}$ \\
\hline Expertise & $\begin{array}{l}\text { A high level of expertise produces more respect from volunteers and the } \\
\text { offering of sharing expertise can also provide for an even greater level of } \\
\text { compliance among individuals. }\end{array}$ \\
\hline Reward & $\begin{array}{l}\text { Reward in the form of accommodation and food has a significant impact } \\
\text { in an organizations ability to obtain compliance from their volunteers. }\end{array}$ \\
\hline
\end{tabular}




\begin{tabular}{|l|l|}
\hline $\begin{array}{l}\text { Delegation of } \\
\text { work }\end{array}$ & $\begin{array}{l}\text { Delegation of work can be used as an organizational control as there are } \\
\text { significant predilections regarding the type of work volunteers want to } \\
\text { conduct, particularly valuable work which produces tangible results. }\end{array}$ \\
\hline $\begin{array}{l}\text { Establishing } \\
\text { free-will }\end{array}$ & $\begin{array}{l}\text { Doing something altruistic by their own choice motivates volunteers. } \\
\text { Creating an autonomous working environment that establishes the free- } \\
\text { will of volunteering will improve volunteer productivity and reduce } \\
\text { counter-productive attitudes. }\end{array}$ \\
\hline
\end{tabular}

Table 2: Synthesized Power and Control Themes

Both emergent themes were found to be inherent within the volunteer tourist-host relationship, predicated on them possessing some degree of altruistic motivation conducive to autonomous working, without the need for coercion. Although the role of altruism as a volunteer motivator is contested in the literature (Terry, 2014; Sin, 2009; Tomazos \& Butler, 2012), our research showed empirical support for enhanced volunteer compliance when altruistic motivations occurred naturally, thus echoing Tomazos and Butler (2012) who suggest reductions in motivations when perceived work obligations are elevated. Furthermore, the emergent themes support previous arguments that volunteers respond best to soft controls such as socioemotional means (Berson \& Sosik, 2007).

Fermenting trust, communication, an intimate working environment, and managerial expertise all demonstrated capacity to yield positive responses from volunteers regarding their commitment to the community and compliance toward working conditions. Surveillance, work delegation, and autonomous freewill despite being more imposing than socioemotional forms of control, were found to produce compliant responses from volunteers. These semi-visible power and control practices were not dependent upon administrators demanding compliance. Rather, our findings supported Foucault's assertion that the self that conforms through his or her own self-discipline (Foucault, 1979). This approach finds particular traction when peers are working hard to portray an altruistic external perception of themselves. Accordingly, subsequent volunteers attempt to exhibit the same self-perception to conform to identities that have been idealized as preferential within the community. Furthermore, our findings suggested certain interactions with different forms of volunteer work produce predilections surrounding specific tasks. As a result volunteers' compliance and work rate would increase when afforded opportunities to produce tangible altruistic results for the community. 
In contrast, visible establishment of power to directly control volunteers was demonstrated to elicit adverse responses. Practices of coercion and establishing job insecurity through volunteer dispensability were, according to our study, ineffective strategies, perhaps principally due to unwillingness of volunteers to accept a paramount administrator of power. The inherent volunteer position, whereby individuals give time of their own volition, facilitated collective feelings shared among the volunteer cohort who were collaborative in negative reaction to, and rejection of, coercive power. Further, our findings mandate decreasing the visibility of control systems as an effective strategy for increasing volunteer compliance due to the desire from volunteers to have 'freewill' in their decision-making. Freewill allowed volunteers space to perceive themselves as altruistically motivated, as they felt they were conducting work without management pressure. During our study, when a visible control system was introduced into the volunteer-host relationship, the self-perception of the 'self' as an altruistic volunteer was replaced by perceived subordination, leading to recalcitrant resistive behaviour. Berson and Sosik (2007) also include remuneration in their categorization of 'hard' control practices, as it is visible and utilizes reward as a promised return in exchange for workforce compliance. Surprisingly issuing greater levels of reward to volunteers was shown to have positive effects on volunteers' compliancy and diminished recalcitrant behaviour. Once the volunteer hosts were willing to offer rewards in exchange for work completed, guiltconscious volunteers found themselves increasingly eager to repay the hosts by exceeding their required workloads. Thus speaking to our understanding of pay for performance systems that continue to be contested within the extant literature (Cadsby et al., 2007; Deckop et al., 1999). The notion that such methods can harness innate altruistic motives finds support in the literature, indicating altruism can motivate volunteers, to foster increased commitment to volunteer tasks, but requires partnership with additional motivation factors (Sin 2009).

\section{Conclusions and Implications}

We contribute to theoretical understanding by developing a new tool (Table 2) to facilitate power and control enhancement commensurate with volunteers' inherent altruistic desires, thus better enabling the effective inducement of appropriate levels of volunteer compliance. More broadly, our study demonstrates the salience of power and control as a theoretical framework to superior-subordinate relationships within a volunteer tourism setting, and in particular, rejects the principle of capital dependency within this context. Furthermore, our results yield insight into the application of control by an administrator not contractually 
obligated to provide appropriate rewards for work conducted, our newly developed framework represents a useful point of departure for future research as well as current management practice. Finally our findings indicate altruism remains relevant, but requires careful management by administrators to identify management practices able to propagate altruistic intentions among their volunteers.

Our study offers several implications for management practice. Principally, the research found that 'softer' forms of control through building relationships, altruistic culture, and autonomous working environments should be employed to provide for the compliance of volunteers. By providing such work environments and culture, guilt consciousness becomes prevalent amongst volunteers and therefore resistive behaviour diminishes. Consequently, establishing altruism as the preferential social identity in the community renders compliance more attainable. Volunteers are likely to become more self-disciplined as they strive to achieve this social identity while under the surveillance of their peers, apathetic identities become unattractive as these perceptions diminish a volunteer's social identity, reputation, and position in the community. We therefore suggest managers emphasise the expectations of their volunteer project, and calibrate marketing and recruitment-stage information to suggestively implant the altruistic motivations purportedly held by volunteers engaging with the project. Additionally, management should augment programmes to include more peer work, and incorporate more team spirit building activities to further grow feelings of camaraderie. Despite voluntary organizations commonly operating in restrictive financial environments, we argue managers of volunteers should consider where feasible, the use of non-financial rewards that reflect volunteer effort and performance. These rewards could manifest in the form of relatively inexpensive, but perceived luxuries such as food items, recreational time, or more comfortable sleeping accommodation. It is suggested that the application of these advisory practices in a host community setting will lead to the diminishment of resistive and hedonistic behaviour identified in volunteer tourism literature (Terry, 2014; Tomazos \& Butler, 2012). Accordingly this will bring about a harmonious working environment that can focus on the sustainable benefits that volunteer tourism offers (McIntosh \& Zahra, 2007). 


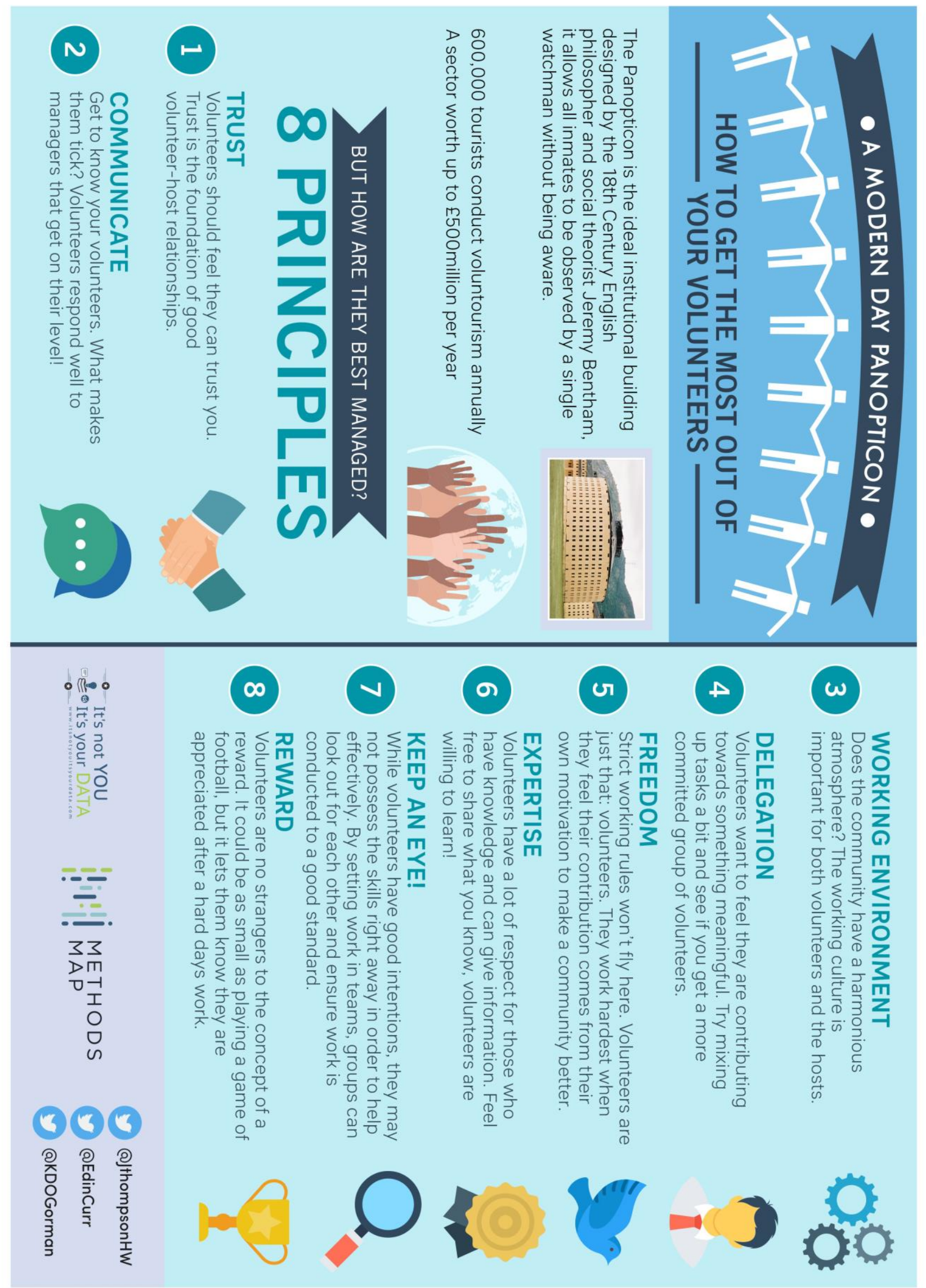

Figure 4: Management Principles 


\section{Limitations and Further Research}

This study was not without its limitations. The auto-ethnographical research design applied in this study has been criticized regarding its objectivity, and reliability (Barbieri et al., 2012). Nevertheless, all reasonable steps were taken to mitigate these issues. For example, the researcher entered the field with no pre-conceptions regarding the possible findings. Results were later discussed among the full research team to contribute to maintaining objectivity. Furthermore, practical steps such as recording interviews, and making detailed field notes were taken by the researcher to enhance the objectivity and reliability of the study. A commonly reported challenge with this research approach, is that of real-time field note keeping (Palacios, 2010), which was not always possible given the other duties ascribed to the researcher. Nevertheless, field notes were updated as soon as possible. Although the community where the fieldwork was based boasted a large quantity and broad cultural diversity of volunteers, the resultant language barrier meant a greater proportion of the research was gathered from conversations with 'western' volunteers from the US or UK, perhaps limiting the studies generalizability and echoing similar challenges faced by previous, related research (Barbieri et al., 2012).

Future research should determine the models appropriateness in differing volunteer tourism contexts and consider additional confirmation through alternative methodological approaches. Interesting differences may occur in host communities that demand a financial contribution from volunteers for involvement. We call for further research regarding developing understanding of how volunteers' interactions with peers, administrators, and symbolic identities of their work influence their attitudes and perceptions. Thus advocating future research utilizing symbolic interactionism as a research philosophy to enhance theoretical understanding and comprehension of how volunteers' attitudes and perceptions are developed in such settings. 


\section{References}

Ainsworth, S. \& Cow, J.W. (2003). Families Divided: Culture and Control in Small Family Business. Organization Studies. 24(9), 1463-1485.

Alexander, Z. (2012) The impact of a volunteer tourism experience, in South Africa, on the tourist: The influence of age, gender, project type and length of stay. Tourism Management Perspectives. 4, 119-126.

Ball, K. \& Wilson, D.C. (2000). Power, Control and Computer-Based Performance Monitoring: Repertoires, Resistance and Subjectivities. Organization Studies. 21(3), 539-565.

Barbieri, C., Santos, C.A. \& Katsube, Y. (2012). Volunteer tourism: On-the-ground observations from Rwanda. Tourism Management. 33(1), 509-516.

Bentham, J. (1843/1791) The Works of Jeremy Bentham, published under the Superintendence of his Executor, John Bowring. Edinburgh: William Tait.

Berson, Y. \& Sosik, J.J. (2007). The Relationship Between Self-Other Rating Agreement and Influence Tactics and Organizational Processes. Group \& Organization Management. 32(6), 675-698.

Boniface, B. \& Cooper, C. (2005). Worldwide Destinations: The Geography of Travel and Tourism. 4th ed. Oxford: Elsevier

Bowen, G.A. (2008). Naturalistic inquiry and the saturation concept: a research note. Qualitative research, 8(1), 137-152

Butler, R., Curran, R., \& O'Gorman, K.D. (2013). Pro-Poor Tourism in a First World Urban Setting: Case Study of Glasgow Govan. International Journal of Tourism Research, 15(5), 443-457.

Cadsby, C.B., Song, F. \& Tapon, F. (2007). Sorting and Incentive Effects of Pay for Performance: An Experimental Investigation. Academy of Management. 50(2), 387405.

Casey, C. (1999). "Come, Join Our Family": Discipline and Integration in Corporate Organizational Culture. Human Relations. 52(1), 155-178.

Choi, S. \& Peng, Y. (2014). Humanized management? Capital and migrant labour in a time of labour shortage in South China. Human Relations. 68(1), 287-304.

Coombs, R., Knights, D. \& Willmott, H. C. (1992). Culture, Control and Competition; Towards a Conceptual Framework for the Study of Information Technology in Organizations. Organization Studies. 13(1), 51-72.

Crowley, M. (2012). Control and Dignity in Professional, Manual and Service-Sector Employment. Organization Studies. 33(10), 1383-1406.

Curran, R., Taheri, B., MacIntosh, R., \& O’Gorman, K. (2016). Nonprofit Brand Heritage: Its Ability to Influence Volunteer Retention, Engagement, and Satisfaction. Nonprofit and Voluntary Sector Quarterly. (Forthcoming).

Deckop, J.R., Mangel, R. \& Cirka, C C. (1999). Research Notes. Getting More Than You Pay For: Organizational Citizenship Behavior and Pay-For-Performance Plans. Academy of Management. 42(4), 420-428.

Degiuli, F. \& Kollmeyer, C. (2007). Bringing Gramsci back in: labor control in Italy's new temporary help industry. Work, Employment \& Society. 21(3), 497-515.

Eisenhardt, K.M. (1985). Control: Organizational and Economic Approaches. Management Science. 31(2), 134-149. 
Elangovan, A.R. \& Xie, J.L. (1999). Effects of perceived power of supervisor on subordinate stress and motivation: the moderating role of subordinate characteristics. Journal of Organizational Behavior. 20(3), 359-373.

Elmes, M.B., Strong, D.M. \& Volkoff, O. (2005). Panoptic empowerment and reflective conformity in enterprise systems-enabled organizations. Information and Organization. 15(1), 1-37

Fleming, P. \& Sturdy, A. (2009). "Just be yourself!": Towards neo-normative control in organisations?. Employee Relations. 31(6), 569 - 583.

Fleming, P. \& Sturdy, A. (2011). 'Being yourself' in the electronic sweatshop: New forms of normative control. Human Relations. 64 (2), 177-200.

Foucault, M. (1979). Discipline and punish: the birth of the prison. New York, Vintage Books.

Foucault, M. (1991). Discipline and Punish: the birth of a prison. London, Penguin.

French, J.R., \& Raven, B.H. (1959). The bases of social power. In D. Cartwright (Ed.), Studies of social power (pp. 150-167). Ann Arbor: Institute for Social Research, University of Michigan.

Frieder, R.E., Hochwarter, W.A. \& DeOrtentiis, P.S. (2015). Attenuating the negative effects of abusive supervision: The role of proactive voice behavior and resource management ability. The Leadership Quarterly. 26(5), 821-837.

Gaventa, J. (2003) Power after Lukes: a review of the literature, Brighton: Institute of Development Studies.

Golden, T.D. \& Veiga, J.F. (2008). The impact of superior-subordinate relationships on the commitment, job satisfaction, and performance of virtual workers. The Leadership Quarterly. 19(1), 77-88.

Goldstein, N.J. \& Hays, N.A. (2011). Illusory Power Transference: The Vicarious Experience of Power. Administrative Science Quarterly. 56(4), 593-621.

Guttentag, D. (2012). Volunteer Tourism: As Good as it Seems? In: Singh, T. V. Critical Debates in Tourism. Bristol: Channel View Publications. 152-159.

Grimm, K.E. \& Needham, M.D. (2012) Internet promotional material and conservation volunteer tourist motivations: A case study of selecting organizations and projects. Tourism Management Perspectives. 1, 17-27

Hales, C. \& Tamangani, Z. (1996). An Investigation of the Relationship Between Organizational Structure, Managerial Role Expectations and Managers' Work Activities. Journal of Management Studies. 33(6), 731-756.

Hechter, M. (2008). The rise and fall of normative control. Accounting, Organizations and Society. 33(6), 663-676.

Hollinshead, K. (1999) Surveillance of the worlds of tourism: Foucault and the eye-of-power. Tourism Management. 20, p7-23.

Iedema, R., Rhodes, C. \& Scheeres, H. (2006). Surveillance, Resistance, Observance: Exploring the Teleo-affective Volatility of Workplace Interaction. Organization Studies. 27(8), 1111-1130.

Iedema, R. \& Rhodes, C. (2010). The Undecided Space of Ethics in Organizational Surveillance. Organization Studies. 31(2), 199-217

Igalens, J. \& Roussel, P. (1999). A study of the relationships between compensation package, work motivation and job satisfaction. Journal of Organizational Behavior. 20(7), 1003-1025. 
Jensen, J. M., \& Raver, J.L. (2012). When selfmanagement and surveillance collide: consequences for employees' organizational citizenship and counterproductive work behaviors. Group \& Organization Management, 37(3), 308-346.

Kacmar, M., K. Witt, L.A., Zivnuska, S. \& Gully, S.M. (2003). The interactive effect of leader-member exchange and communication frequency on performance ratings. Journal of Applied Psychology. 88(4), 764-772.

Kinnie, N., Hutchinson, S. \& Purcell, J. (2000). 'Fun and surveillance': the paradox of high commitment management in call centres. The International Journal of Human Resource Management. 11(5), 967-985.

Kunda, G. (1992), Engineering Culture: Control and Commitment in a High-Tech Corporation, Temple University Press, Philadelphia, PA.

Levine, D.I. (1992). Can Wage Increases Pay For Themselves? Tests with a Productive Function. The Economic Journal. 102(414), 1102-1115.

Lines, R. (2007). Using Power to Install Strategy: The Relationships between Expert Power, Position Power, Influence Tactics and Implementation Success. Journal of Change Management. 7(2), 143-170.

Loi, R., Lai, J. \& Lam, L. (2012). Working under a committed boss: A test of the relationship between supervisors' and subordinates' affective commitment. The Leadership Quarterly. 23(3), 466-475.

Lupoli, C.A., Morse, W.C., Bailey C. \& Schelhas J. (2015) Indicator development methodology for volunteer tourism in host communities: creating a low-cost, locally applicable, rapid assessment tool. Journal of Sustainable Tourism. 23(5), 726-747.

Mackey, J.D., Ellen, P.B., Hochwarter, W.A. \& Ferris, G.R. (2013). Subordinate social adaptability and the consequences of abusive supervision perceptions in two samples. The Leadership Quarterly. 24(5), 732-746.

Mann, S., Nolan, J. \& Wellman, B. (2003). Sousveillance: Inventing and Using Wearable Computing Devices for Data Collection in Surveillance Environments. Surveillance \& Society. 1(3), 331-355.

McCauley, D.P. \& Kuhnert, K.W. (1992). A Theoretical Review and Empirical Investigation of Employee Trust in Management. Public Administration Quarterly. 16(2), 265-284.

McGehee, N.G. (2014) Volunteer tourism: evolution, issues and futures. Journal of Sustainable Tourism. 22(6), 847-854

McIntosh, A.J. \& Zahra, A. (2007). A Cultural Encounter through Volunteer Tourism: Towards the Ideals of Sustainable Tourism?. Journal of Sustainable Tourism. 15(5), 541-556.

McMillan, C.L., O'Gorman, K.D., \& MacLaren, A.C. (2011). Commercial hospitality: a vehicle for the sustainable empowerment of Nepali women. International Journal of Contemporary Hospitality Management, 23(2), 189-208.

Mulinge, M.M. (2001). Employers control of employees: Extending the Lincoln-Kalleberg corporatist model of satisfaction and attachment. Human Relations. 54(3), 285-318.

Nyahunzvi, D.K. (2013) Come and make a real difference: Online marketing of the volunteering experience to Zimbabwe. Tourism Management Perspectives. 7, p83-88

O'Gorman, K.D. and MacIntosh, R. (2015) Research Methods for Business Management: A Guide to writing your dissertation. Goodfellow, Oxford. 
O'Gorman, K.D., MacLaren, A. and Bryce, D. (2014) A Call for Renewal in Ethnographic Research: The researcher as both the subject and object of knowledge. Current Issues in Tourism. 17(1), 46-59.

Otoo, F.E. \& Amuquandoh, F.E. (2014) An exploration of the motivations for volunteering: A study of international volunteer tourists to Ghana. Tourism Management Perspectives. 11, 51-57.

Palacios, C.M. (2010). Volunteer tourism, development and education in a postcolonial world: conceiving global connections beyond aid. Journal of Sustainable Tourism. 18(7), 861-878.

Podsakoff, P.M. \& Schriesheim, C.A. (1985). Field Studies of French and Raven's Bases of Power: Critique, Reanalysis, and Suggestions for Future Research. Psychological Bulletin. 97(3), 387-411.

Podsakoff, P.M., Todor, W.D. \& Skov, R. (1982). Effects of leader contingent and noncontingent reward and punishment behaviors on subordinate performance and satisfaction. Academy of Management Journal, 25(4), 810-821

Podsakoff, P.M., Todor, W.D., Grover, R.A. \& Huber, V.L. (1984). Situational moderators of leader reward and punishment behaviors: Fact or fiction? Organizational Behavior and Human Performance, 34(1), 21-63.

Podsakoff, P.M. \& Todor, W.D. (1985). Relationships Between Leader Reward and Punishment Behavior and Group Processes and Productivity. Journal of Management. 11(1), 55-73.

Preuss, L., Haunschild, A. \& Matten, D. (2009). The rise of CSR: implications for HRM and employee representation. The International Journal of Human Resource Management. 20(4), 953-973.

Rahim, M.A. (1989). Relationships of Leader Power to Compliance and Satisfaction with Supervision: Evidence from a National Sample of Managers. Journal of Management. 15(4), 545-556.

Raven, B.H. (1965). Social influence and power. In I.D. Steiner \& M. Fishbein (Eds.), Current studies in social psychology (pp. 371-382). New York: Holt, Rinehart, Winston.

Raven, B.H. (1992). A power/interaction model of interpersonal influence: French and Raven thirty years later. Journal of Social Behavior and Personality. 7(2), 217-244.

Raven, B.H. (1993). The bases of power: Origins and recent developments. Journal of Social Issues. 49(4), 227-251.

Raven, B.H. (1999). Kurt Lewin Address: Influence, Power, Religion, and the Mechanisms of Social Control. Journal of Social Issues. 55(1), 161-186.

Raven, B.H. (2008). The Bases of Power and the Power/Interaction Model of Interpersonal Influence. Analyses of Social Issues and Public Policy. 8(1), 1-22.

Reed, M.I. (2001). Organization, Trust and Control: A Realist Analysis. Organization Studies. 22(2), 201-228.

Sanchez, R. \& Toharia, L. (2000). Temporary workers and productivity: the case of Spain. Applied Economics. 32(5), 583-591.

Schnake, M.E. (1986). Vicarious punishment in a work setting. Journal of Applied Psychology. 71(2), 343-345. 
Sewell, G. \& Wilkinson, B. (1992). Empowerment or Emasculation? Shopfloor Surveillance in a Total Quality Organization. In: Blyton, P. Turnbull, P. Blyton, P. \& Turnbull, P. J. Reassessing Human Resource Management. London: SAGE. 97-115.

Sewell, G. (1998). The Discipline of Teams: The Control of Team-Based Industrial Work through Electronic and Peer Surveillance. Administrative Science Quarterly. 43(2), 397-428.

Singh, T.V. (2012). Introduction. In: Singh, T. V. Critical Debates in Tourism. Bristol: Channel View Publications. 1-26.

Sin, C.H. (2003). Interviewing in 'place': the socio-spatial construction of interview data. Area. 35(3), 305-312.

Sin, H.L. (2009). Volunteer Tourism - 'Involve me and I will Learn'?. Annals of Tourism Research. 36(3), 480-501.

Shamir, B. \& Lapidot, Y. (2003). Trust in Organizational Superiors: Systemic and Collective Considerations. Organization Studies. 24(3), 463-491.

Smith, V.L. \& Font, X. (2014). Volunteer tourism, greenwashing and understanding responsible marketing using market signalling theory. Journal of Sustainable Tourism. 22(6), 942-963.

Streifeneder, T. (2016) Agriculture first: Assessing European policies and scientific typologies to define authentic agritourism and differentiate it from countryside tourism. Tourism Management Perspectives. 20, p251-264

Studer, S., \& von Schnurbein, G. (2013). Organizational factors affecting volunteers: A literature review on volunteer coordination. VOLUNTAS: International Journal of Voluntary and Nonprofit Organizations, 24(2), 403-440.

Stukas, A.A., Snyder, M. \& Clary, E.G. (1999). The Effects of Mandatory Volunteerism on Intentions to Volunteer. Psychological Science. 10(1), 59-64.

Styhre, A. (2008). Management Control in Bureaucratic and Postbureaucratic Organizations: A Lacanian Perspective. Group Organization Management. 33(6), 635-656.

Subašić, E., Reynolds, K.J., Turner, J.C., Veenstra, K.E. \& Haslam, A. (2011). Leadership, power and the use of surveillance: Implications of shared social identity for leaders' capacity to influence. The Leadership Quarterly. 22(1), 170-181.

Taskin, L. \& Bunnen, G.V. (2015). Knowledge management through the development of knowledge repositories: towards work degradation. New Technology, Work and Employment. 30(2), 158-172.

Tenbrunsel, A.E. \& Messick, D.M. (1999). Sanctioning Systems, Decision Frames, and Cooperation. Administrative Science Quarterly. 44(4), 684-707.

Terry, W. (2014). Solving labor problems and building capacity unsustainable agriculture through volunteer tourism. Annals of Tourism Research. 49(1), 94-107.

Tomazos, K \& Butler, R. (2012). Volunteer tourists in the field: A question of balance? Tourism Management. 33(1), 177-187.

Trevino, L.K. (1992). The Social Effects of Punishment in Organizations: A Justice Perspective. The Academy of Management Review. 17(4), 647-676.

Vázquez, X.H. (2006). An Eclectic Explanation of Shopfloor Control Using Efficiency and Power Theories. Organization Studies. 27(10), 1421-1446.

Walton, E.J. (2005). The Persistence of Bureaucracy: A Meta-analysis of Weber's Model of Bureaucratic Control. Organization Studies. 26(4), 569-600.

Wearing, S. (2001). Volunteer Tourism: Experiences That Make a Difference. Oxon: CABI. 
Wearing, S., \& McGehee, N. G. (2013). Volunteer tourism: A review. Tourism Management, 38, 120-130.

World Bank Data. (2013). International tourism, number of arrivals. Available: http://data.worldbank.org/indicator/ST.INT.ARVL/countries/BO?display=graph from $9^{\text {th }}$ June 2015

Zarandian, N., Shalbafian, A., Ryan, C. \& Bidokhti, A.A. (2016) Islamic pro-poor and volunteer tourism - The impacts on tourists: A case study of Shabake Talayedaran Jihad, Teheran - A research note. Tourism Management Perspectives. 19(B), p165169. 